\title{
Embedding Virtual Reality Technology in Teaching 3D Design for Secondary Education
}

\author{
Mutian Niu, Cheng-Hung Lo* and Zhiyuan Yu \\ School of Film and TV Arts, Xi'an Jiaotong-Liverpool University, Suzhou, China
}

\section{OPEN ACCESS}

Edited by:

Tien-Chi Huang,

National Taichung University of Science and Technology, Taiwan

Reviewed by:

Chansik Park

Chung-Ang University, South Korea

Fang-Chuan Ou Yang,

Providence University, Taiwan

*Correspondence:

Cheng-Hung Lo

ch.lo@xitlu.edu.cn

Specialty section:

This article was submitted to Virtual Reality and Human Behaviour,

a section of the journal

Frontiers in Virtual Reality

Received: 31 January 2021

Accepted: 05 May 2021

Published: 28 May 2021

Citation:

Niu M, Lo C-H and Yu Z (2021) Embedding Virtual Reality Technology

in Teaching 3D Design for

Secondary Education.

Front. Virtual Real. 2:661920.

doi: $10.3389 /$ frvir.2021.661920
As a new medium in modern education, virtual reality technology has stimulated the changes of pedagogical practice and added further opportunities for experiential learning. The immersive and interactive experience of VR fits seemingly well with practical subjects such as Creative Design. Design-related courses in secondary education usually appeal to the students with their practical elements, which also help in developing a student's creative and cognitive ability. The dual coding learning theory states that the learning process can be improved by using the symmetrical visual and language systems of the left and right hemispheres. This paper presents a novel teaching framework that combines classroom learning with VR technology. We devise the course structure based on Bloom's Taxonomy and fill in knowledge and skills related to 3D Design. In collaboration with a local school, we implemented and delivered the proposed course to a group of students. After the course, we use questionnaires and interviews to collect and analyze the attendees' feedback. The results show that the interactive experience in VR coincides better with the students' perception of 3D conceptual design. The teaching methods are also wellreceived by them. Based on the findings, we suggest that immersive VR technology is a promising tool for developing practical courses such as product design and development.

Keywords: education technology, virtual reality, dual coding theory, design education, student creativity, pedagogical framework

\section{INTRODUCTION}

Design is one of the important subject areas included in STEAM education (Science, Technology, Engineering, Art, and Mathematics). Many educators believe that STEAM education can improve aesthetic appreciation and achieve the effect of interdisciplinary collaboration so as to cultivate students' creativity and critical thinking (Prezhdarova and Pastarmadzhieva, 2020). Graham (2020) argued that design education naturally integrated art, science, and technology to improve a student's cognitive and practical skills. Design education shall thus be a comprehensive concept that connects "imagination" and "planning" to achieve "purposeful creation" (Zhang, 2018). The elements of a successful learning process should include the effective teaching modes, appropriate teaching tools, and the arrangement of teaching activities (Laurillard et al., 2013). These elements are required educators to balance the relationship among the three in the process of curriculum arrangement. In terms of design education, the conceptual knowledge and design practice are intertwined in cultivating students to establish the understanding of design technology.

The Dual Coding theory (DCT) proposed by Paivio (1991) puts visual and verbal cognition in equally-important positions for learning new knowledge (Liu et al., 2020). Mayer and Anderson 
(1991) found that the learning effect of verbal or visual interpretation alone was not as good as that of coordinated interpretation combining verbal and visual interpretation. By utilizing the visual and verbal systems that are symmetrical in both the left and right hemispheres of the brain, a student's learning process can be significantly improved (Suh and MoyerPackenham, 2007). With the emergence of immersive technology, the learning process can be enriched by including more channels of information (Barari et al., 2020). Dahlstrom and Bichsel (2013) stated that one critical issue of technology uses in education was the educators' ability to integrate technology seamlessly into the pedagogical framework. Educators shall design a learning experience to meet the learners' needs but simply introduce new technologies as an isolated agenda. Many studies have shown that Virtual Reality can positively influence students' learning result in design (Allcoat and von-Mühlenen, 2018; Meyer et al., 2019; Radianti et al., 2020). For example, combining immersive VR with $3 \mathrm{D}$ modeling so that students could learn with a more intuitive and responsive process (Bruno et al., 2007; Jimeno-Morenilla et al., 2016; Liang et al., 2016; Camba et al., 2017; Hamurcu, 2018; Shih et al., 2019). VR technology could also help motivate the students in secondary school (Tang et al., 2020) and bring a new perspective to the course delivery. The immersive visual experience provided by VR seems to enhance the visual content of DCT theory, especially in the field of design education, which has specific requirements for 3D space understanding.

As a learning medium, VR is advantageous in letting students interact directly with design models, thus simulating better the physical manipulation in reality. However, according to the review in Radianti et al. (2020), most of current research focused on developing different VR learning applications. Moreover, many related courses used desktop-based panoramic imagery, instead of immersive display, to provide simulated training of specific tasks (Lin and Hsu, 2017), which may not be suitable for students at the early stages of learning design, where heuristics, divergent thinking, and intermediate reflection often take place. The design course of secondary education is committed to inspiring students' design thinking and understanding, and the way of introducing VR technology into the education process and the degree of achieving the expected education effect are worth discussing. In this paper, our study was initiated in response to the following questions: 1) how to embed immersive technology in the design course of secondary education for students to learn basic design expression skills? 2) how do the students evaluate their learning experience and achievements after completing the design course based on VR? We aim to: 1) bridge the subject learning and immersive learning with a proposed pedagogical framework, 2) analyze the students' needs and evaluate such a framework to inform design educators who wish to integrate immersive VR technology into their teaching. The rest of this paper is structured as follows: "Related Works" presents the current research in dual coding theory and VR education. In "Methodology", we elaborate the proposed pedagogical framework and course structure. The course feedback collected through the questionnaires and interviews are analyzed and discussed in "Analysis and
Discussion of the Learners' Feedback". We then conclude the work in "Conclusion".

\section{RELATED WORKS}

\section{Dual Coding Theory and Learning Style}

Many researchers proposed teaching methods suitable for different types of learners and integrated them into educational practice (Demirbas and Demirkan, 2003; Kvan and Jia, 2005). Several studies also showed that when the teaching mode matches the students' learning style, a better learning effect could be achieved (Mahlios, 2001; Stanberry and Azria-Evans, 2001; Ogden, 2003; Lovelace, 2005; Naimie et al., 2010). On the other hand, Pashler et al. (2008) found that only few studies supported the direct effect of learning style on student performance. Most of these studies are based on experiential learning theory (Demirkan and Demirbas, 2008; Amran et al., 2011; Muscat and Mollicone, 2012). The results are often related to individuals and difficult to be accounted for a unified teaching mode. Cuevas and Dawson (2018) argued that learning style was not necessarily an effective element in teaching, whereas the dual coding theory might be more beneficial to developing teaching approaches. The DCT puts forward a hypothesis that memory information is processed by two interconnected coding (verbal and visual) systems (Paivio, 1991). In other words, DCT promotes an individual's innate capability of encoding the information into verbal and visual systems, and the dual processes are interrelated but functionally independent (Hodes, 1998; Cuevas, 2016). This claim is mainly based on the brain's left and right hemispheres to work in parallel, the left processing language, the right processing visual-spatial information. Some studies found that when both hemispheres of the brain were activated, the comprehensive processing of information would improve people's memory performance (Funnell et al., 2001; Gazzaniga, 2005). To validate DCT, most studies focused on comparing abstract vocabulary comprehension and recall (Sharps et al., 1996; Jessen et al., 2000; Mazoyer et al., 2002; Welcome et al., 2011). A large number of verbal stimuli could lead to cognitive overload and partial information loss. Visual information stored separately could achieve the additional effect of memory retention. In Jessen et al. (2000), the researchers found that the participants' visual performance were related more to $3 \mathrm{D}$ spatial stimuli, rather than 2D images. Similarly, Funnell et al. (2003), pointed out that human spatial perception depended mostly on visual processing. In terms of design education, visual information is very important in students' judgment on shapes and forms, which in consequence influence their understanding of design concepts.

\section{Virtual Reality in Education}

Emerging technologies such as VR create new learning opportunities, strategies, and methods. Dabbagh (2003) pointed out that the learning effect relied on the good coordination of education modes, learning methods, and teaching tools. VR technologies can be regarded as a teaching tool for delivering education. The interactive learning feature 
provided by VR can enhance a learner's creativity (Fowler, 2015; Cai et al., 2019; Barari et al., 2020), which benefits design education. Krokos et al. (2019) showed that students could better apply their knowledge after using VR for practice. Barari et al. (2020) proposed that VR-aided teaching approaches could access the learning objectives at different levels in Bloom's taxonomy.

Many studies have verified and recognized the application influence of VR in training (Stone, 2001; Lee and Wong, 2008). Liang et al. (2016) built a designer-oriented VR system for students majoring in industrial design, which is different from the traditional commercial software on the market, to help students better understand industrial design. Similarly, Nguyen and Dang (2017) proposed a model for educators to build the structure guidelines of the educational application by using VR and AR. Lin and Hsu (2017) used desktop-VR to improve the content of architectural education courses and got better feedback from students. Chung et al. (2020) explored the ability indices of VR technology on the teaching of a welding practice course and verified the effectiveness of the teaching modes. In particular, Jones et al. (2016) indicated that VR technology has the ability to attract students by improving the teaching content that students are interested in, which can let the VR distinguish from the traditional learning approaches.

Similarly, VR has been applied to secondary education by many research. Jensen and Konradsen (2018) systematically reviewed the past literature and concluded that the advantage of VR for STEAM education is to provide an effective way to improve new perception technology to enhance students' learning motivation. Maheshwari and Maheshwari (2020) showed that VR enables students to interact with 3D objects, conducive to visualizing conceptual knowledge and making students understand it more comprehensively. Zhang et al. (2020) found no significant difference between VR and traditional teaching media unless the unstructured knowledge is delivered and the use of VR reduces the learning pressure of some students. On this point, Sulaiman et al. (2020) also found that VR as a teaching tool can promote students' learning of physics concepts that are difficult to understand in secondary school. In addition to design courses, Guerrero et al. (2016) combined the geometry interface created by VR to provide a higher level of knowledge in secondary school geometry learning, which was also confirmed by Brinson (2015). Due to the weak of the learners' interest in STEAM education in secondary school, Bogusevschi et al. (2020) agreed that VR could improve the students' enthusiasm in the courses.

Meanwhile, some research focused on applying 3D software like $\mathrm{CAD}$ to enhance their perception of the creative skill for design education (Wang, 2001; Sampaio et al., 2010; Dinis et al., 2017; Nguyen and Dang, 2017). However, these studies are designed for students with a particular design basis, many of them are designed for college students or students with specific skills, but they are relatively complex for students in secondary school. Nevertheless, these studies also prove the benefits of VR to design education. Noel and Liub (2017) indicated that the developed focus of design-based STEAM education is to encourage students to create design solutions and implement design thinking into secondary education, providing a primary foundation and skills for future professionals engaged in the design and knowledge-based industries. Therefore, as for design education in secondary school, inspiration and exploration are the key points of curriculum design.

\section{METHODOLOGY}

\section{Overview}

Virtual Reality can be useful to education, but the premise to achieve this effect is the appropriate combination of delivery modes and tools. We hope the curriculum design can reflect the way students master how to express and present the design concepts with VR. Our goal is to provide a complete pedagogical framework, including the whole VR-based design curriculum from planning to implementation. This research takes the students in secondary education as the target learners. We propose a pedagogical framework embedded with VR technology. The whole research process is shown in Figure 1. Based on the idea of DCT, we gathered the relevant content and set the general delivery modes of the course. Bloom's taxonomy is then used in the development of the course structure as the basis to ensure the rationality of curriculum design. Finally, we collected the students' feedback through questionnaires and interviews to evaluate the proposed course. We aimed to use VR to induce the students' imaginative and expressive abilities contributing to basic "design expression" skills.

The learning goals and objectives for students can be summarized as follows:

1) Understand the basic conceptual and operational knowledge of VR;

2) Understand the concept of design and its process;

3) Have the ability to use VR to express/generate design concepts in $3 \mathrm{D}$ forms

\section{Course Attendees and Arrangement}

This study was carried out with a collaborated local school. Our courses were delivered for three class groups of students in the first grade (age of 13-14) in this secondary school. A total of 72 students ( 37 males and 35 females) from the three classes (23 in the first class, 24 in the second, and 25 in the third) participated in the study. We implemented the pedagogical framework as a technical course that lasted for 15 weeks with one contacting hour per week for each class group. The designated classroom includes four activity spaces with VR devices (two sets of HTC Vive and two sets of Oculus rift), as well as a spacious lecture area. Two teaching staff contributed to the delivery of the course.

\section{Course Design Course Content}

As discussed earlier, DCT stated that students could better understand the knowledge and concept through verbal and visual system processing (Cuevas, 2016). We invited three teachers with the industrial design background to participate in the focus group to extract the design course content, 


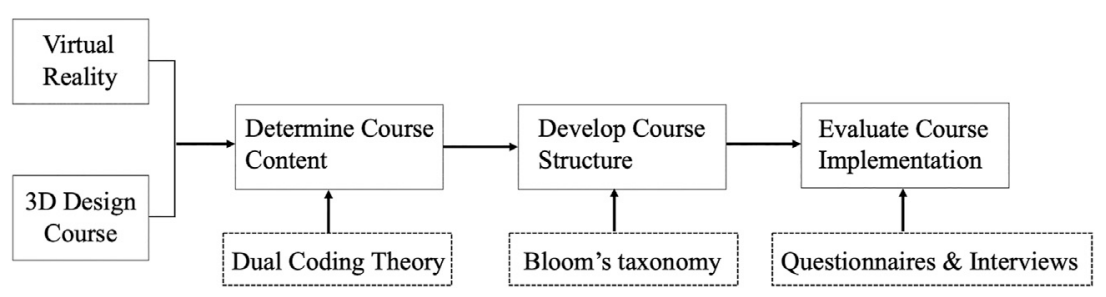

FIGURE 1 | Research Flowchart.

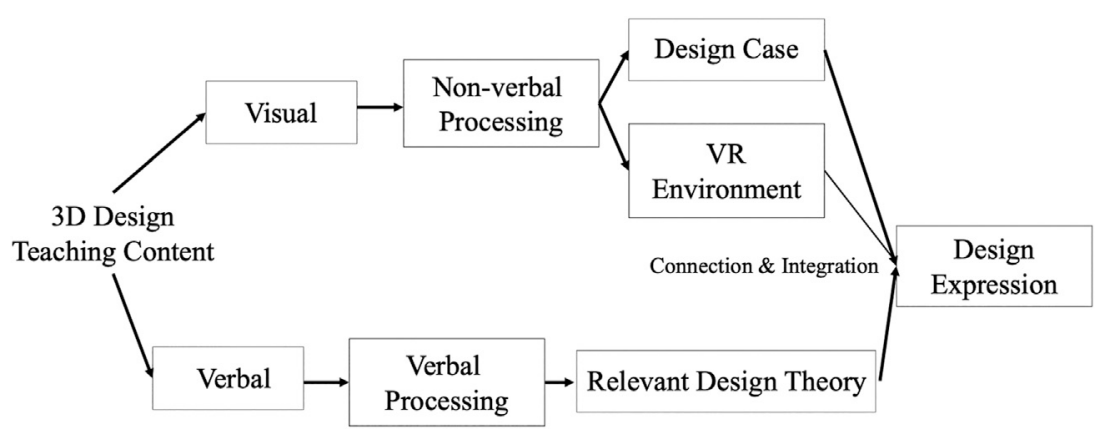

FIGURE 2 | The content structure of the course.

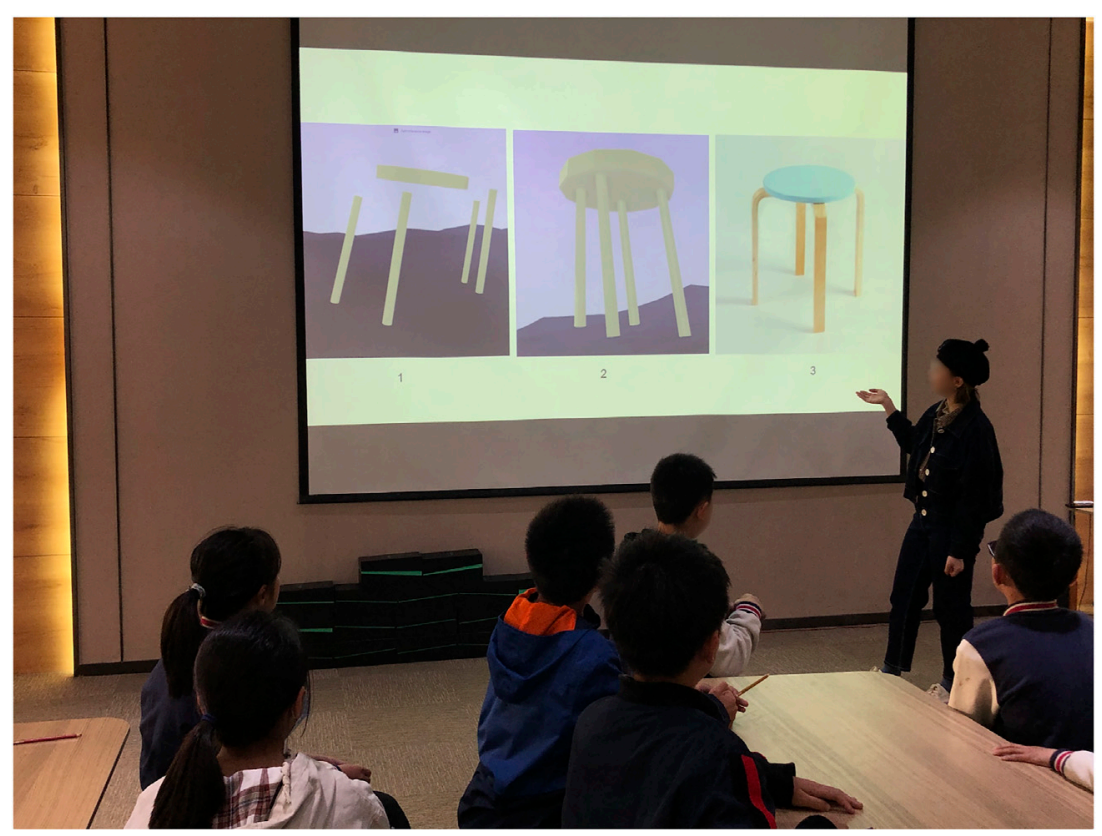

FIGURE 3 | The lecture of 3D modelling based on DCT theory to express the modeling principle.

summarize and analyze the verbal and visual content in these course content. Most of the students who attended the course were novice learner who did not possess knowledge of design but only interests. The focus is, therefore, to develop the students' creative thinking by using VR. Zhang et al. (2020) pointed out that educators should pay more attention to the inquiry skills cultivation. The design course's main content is $3 \mathrm{D}$ model design, which is mainly because activities such as design and prototype construction help to cultivate students' creative thinking and problem-solving ability (Siew, 2017). VR's stereo perspective can 


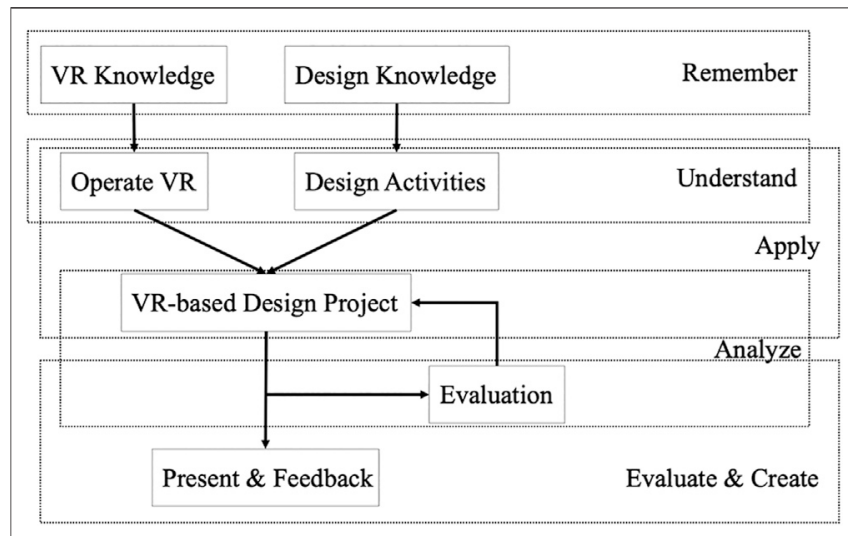

FIGURE 4 | The pedagogical framework

meet the 3D space and intuitive operation mode needed by $3 \mathrm{D}$ model design. The 3D design selected in this course is not a simple design activity but an exploratory design project. Therefore, the course requires students to master the technology of operating 3D models and to cultivate their ability to deal with the whole design process.

We adapted the DCT design framework proposed by Liu et al. (2020) and generated the content layout accordingly. According to the discussion results of the focus group, the verbal content mainly involves some relevant design theories or design concepts that are difficult to understand. We used the visual materials to help students better understand the meaning of some theoretical terms and design theories, which first need some figures and design cases to explain. Besides, for the content of 3D space perception mentioned in the verbal part, a VR environment is needed to guide students to learn. As shown in Figure 2, to help students achieve a better cognitive performance in storing and processing information, we specified the linguistic-based content and the visual content and their corresponding deliveries in our course. For example, as shown in Figure 3, we built the basic visual 3D modeling and model explosion diagram of the product model. Through three groups of pictures to show the students the modeling process or the back-stepping process of the design. To help students quickly analyze the product shape, understand that product design is not only focused on the concept of shape but also considers the combination and assembly effect of $3 \mathrm{D}$ geometry. In this part of the course, we focus on the analysis of product modeling. We chose to use relatively less complex geometry and product models. In the content of the collection, we focus on the analysis of product modeling.

\section{Pedagogical Framework}

Our pedagogical framework is based on Bloom's taxonomy revised by Anderson and Bloom (2001). Bloom (1956) created a taxonomy of six elements in learning and classified the common educational goals, to ensure the rationality of the framework and students can master all stages of the cognitive field in learning. The revised taxonomy defines the six elements as the six processes of remembering, understanding, applying, analysing, evaluating, and creating. This study aims to develop the necessary education process and teaching indicators for the design curriculum of secondary school, in order to achieve the required learning objectives. The proposed pedagogical framework is shown in Figure 4 and described in Table 1.

1) Introduction to VR: For learners without VR experience, exploring a $3 \mathrm{D}$ virtual environment may lead to cognitive overload (Pellas and Boumpa, 2017). The premise of implementing this course content is that students can skillfully use VR equipment. In the initial stage of the course, we introduce VR related knowledge and the basic operations of VR systems. This introductory stage lasts about 3 weeks. This content of this part mainly corresponds with the three fundamental processes in Bloom's taxonomy. We adopt the mode of half teaching and half practice in the first 3 weeks of the course. The teaching part mainly involves the development and characteristics of VR technology, which is carried out on memory and maintenance content in the cognitive field. The practice part is a course for students to experience VR so that students can cross-use two different VR devices provided by our classroom, and implement the teaching content into the practice process, which will enhance learners' understanding of VR. The practice process will promote learners to the third level, that is, the application of knowledge.

2) 3D design basics: Because the theme of the course is about 3D design, the students need to establish a conceptual understanding of design and its process. We arranged manual activities, instead of sketching or computer operations during this period, to let students think in 3D without the limitation of a $2 \mathrm{D}$ plane, which is also the essence of introducing VR as a means of design education. This stage lasts about 4 weeks. The first 2 weeks of the design course mainly include the theory and process of 3D design, which also involves the stage of memory and understanding. The design process of the 3D model can be regarded as the modification and assembly of the models, so we arranged a manual course to collage and assemble the geometry models to deepen students' understanding of the $3 \mathrm{D}$ model. This stage involves the understanding and application of bloom taxonomy.

3) Project assignment: Sims and Shreeve (2012) advocated that the process of art design education is "dialogic," which means that the interaction process between students and teachers, students and knowledge content, and students and students is continuous. This session dedicates to a group assignment to achieve the "dialogic" learning effect in group members' cooperation. The course form is similar to the design studio. The students are asked to think about the design theme and create it with the VR equipment. We do not want to limit the students' creative scope, henceforth the open theme. The students work as groups till the completion of the projects. In order to complete the design project, we need modelling software using virtual reality technology, which can create $3 \mathrm{D}$ models in the virtual environment and modify and optimize them. We incorporate a VR modelling software freely available online (produced by Google) for the students to express and refine their ideas and design concepts to produce the final models. The software can support the use of Oculus and HTC Vive, and other devices to meet the type of equipment in our classroom. In addition, this software has a friendly tutorial in the initial use 
TABLE 1 | Pedagogical framework based on revised bloom's taxonomy.

\begin{tabular}{|c|c|c|c|}
\hline Phase & Content & Duration & Bloom's taxonomy \\
\hline Introduction & $\begin{array}{l}\text { Lecture about VR: } \\
\text { - Introduce about VR knowledge } \\
\text { - How to use VR devices } \\
\text { - Experience and master how to use }\end{array}$ & 3 weeks & Remember, understand, apply \\
\hline Design teaching & $\begin{array}{l}\text { Lecture about design: } \\
\text { - Introduce about design knowledge } \\
\text { - Understand the 3D design } \\
\text { - Experience 3D design - handmade } \\
\text { - Understand design process }\end{array}$ & 4 weeks & Remember, understand, apply \\
\hline Project assignment & $\begin{array}{l}\text { Explain project requirements } \\
\text { Teamwork }\end{array}$ & 6 weeks & Apply, analyze \\
\hline Assessment & $\begin{array}{l}\text { Present the work } \\
\text { Communication and feedback }\end{array}$ & 2 weeks & Evaluate, create \\
\hline
\end{tabular}

stage, which undoubtedly helps students to understand and be familiar with the operation method of the software more quickly. Vande Zande et al. (2014) pointed out that design education can help students develop the ability to solve problems through the design process. At this stage, the students need to consider the design goals, how to implement them, and the distribution of the work among group members. They play the role of designers, experience the design process, and learn how to cooperate with each other. In the design activities of students modeling by VR software, students apply the design knowledge and the way of using VR devices to the design activities according to the previous learning. The cognitive stage of their self-evaluation accompanies the process of students modifying and improving the design project.

4) Assessment: At the end of the course, we organize a class demonstration. Each group shows their design outcome and gives a presentation about their design concept and design process in turn. The other groups together with teachers to evaluate and discuss these design works. The assessment stage lasts 2 weeks. In the first week, we conduct the assessment activities, and students will get their design feedback. In the next week, students will optimize their design work based on their feedback. During the 2 week cognitive process, students use critical thinking to evaluate other people's works, and at the same time, combined with the evaluation results, students reflect on their design to create new value.

\section{Course Assessment}

Considering that this is an introductory design course in secondary education, we arrange mainly class exercises and one final group project in the course. The theme of the project is open and not graded by paper-based examination, which aims to quantify the degree of their design work (Takala et al., 2016). In terms of assessing, we focus on the students' understanding of design process and basic working knowledge of $\mathrm{VR}$, instead of the aesthetic quality of the design work (Bevins and Price, 2016).

\section{ANALYSIS AND DISCUSSION OF THE LEARNERS' FEEDBACK}

We collected the students' feedback via both quantitative and qualitative means. After 15 weeks of teaching, a questionnaire

\section{TABLE 2 | The feedback questionnaire.}

No.

Q1

Q2

Q3

Q4

Q5

Q6

Q7

Q8

Q9

Q10

Q11

Q12

\section{Questionnaire}

I know how to express my design ideas with VR

I have experienced the whole design process

I feel creative in the course

I have a deeper understanding of design

I have mastered the learning content completely

I know how to communicate my ideas in the design process

I can share my design ideas with my classmates

I am satisfied with my final design

It is reasonable to use VR to create design works

This VR course has a clear plan

VR can help me better understand the design concept

The teaching approaches used in the course fit my study habits survey was given to each student who attended the course. The questionnaire focused mainly on students' self-learning and reflection on their experience in the course. The questionnaire contains a series of statements attached with the Likert-type of scale. Each statement is to be rated with one to five points, in which one represents a strong disagreement, and five represents a strong agreement. The questionnaire's design is designed and revised based on the research of Kuo et al. (2017), which has great potential as a reference tool for educational institutions to evaluate the implementation and practice of innovative education. The total 12 statements are shown in Table 2. The content of the questionnaire involves three dimensions:

1) the feeling of VR (Q1, Q9, Q11);

2) the understanding of course content (Q2, Q4, Q5, Q6), which also reflects the evaluation of DCT-based course structure;

3) the experience and feeling of the design course (Q3, Q7, Q8, Q10, Q12)

For the qualitative feedback, we carried out a follow-up interview to explore further the students' attitudes and ideas towards the course.

\section{Questionnaire Data Analysis}

The questionnaire was distributed to each student who attended the course to collect students' opinion and feedback of the design 
TABLE 3 | The reliability analysis of the questionnaire.

\begin{tabular}{lc}
\hline Cronbach's alpha & N of items \\
\hline 0.869 & 12
\end{tabular}

TABLE 4 | The validity analysis of the questionnaire.

Kaiser-meyer-olkin measure of sampling adequacy.

0.815

Bartlett's test of sphericity

Approx. Chi-square

df

Sig.

217.003

66

0.000

course. Therefore, a total of 72 questionnaires were collected. After removing those of uncompleted or completed with highlydisruptive responses, 60 of them were considered as the valid data for further analysis. We run a reliability test with the valid responses. As shown in Tables 3 Tables 4, the resulted Cronbach's Alpha value is 0.869 , which indicates the responses are highly consistent and supported with statistical significance $(p<0.05)$.

The readers are kindly recalled that in our questionnaire, rating of one is "strongly disagree" and that of five is "strongly agree". As a result, the higher a statement's average rating, the stronger the students' agreeableness to the statement. The descriptive statistics of the ratings are shown in Table 5. The overall ratings (ranged from 3.38 to 4.48 ) indicate that the students gave positive responses to the listed statements. Among them, Q9 scores the highest. The students agreed that using VR to carry out 3D design is a reasonable approach. Despite the overall positive responses, Q1 and Q5 received relatively lower ratings. The students might have certain hesitations in claiming their confidence of expressing design ideas with VR and the mastery of the taught content. We thus focused on these two aspects in the follow-up interview.

Pearson correlation analysis was used to establish the correlation among the responses. The correlation coefficients are collated as the correlation matrix shown in Table 6 . It can be seen that all the responses to the statements are positively correlated, though some of them are statistically insignificant. We found a positive correlation between Q1 and Q5 ( $\mathrm{r}=0.503, p<$ 0.01 ), which shows the mastery level of the taught content increases or decreases with the VR expressive skills. Moreover, Q1 and Q2 have the highest correlation ( $r=0.607, p<0.01)$. This implies that if a student is confident in using VR to express design ideas, he or she perceives a more complete design process. Q3, Q11, and Q12 ( $\mathrm{r}=0.535,0.506$, and 0.557) also have the higher positive correlations with Q2. Experiencing the design process are tied in with the empowerment of creativity, the aid of VR, and the incorporated teaching methods. These phenomena support our initiative of embedding VR technology in teaching design. And for most students, the pedagogical framework does help them achieve the set learning outcomes of this design course.

Q3 is strongly correlated with Q4 $(\mathrm{r}=0.608, p<0.01)$, in which case exhibits the highest correlation among all the responses. The perceived creativity changes in accordance with the understanding of design. It is worth mentioning here that no significant correlation was found between Q4 and Q11. However, the correlation between Q4 and Q1 is high ( $\mathrm{r}=0.582, p<0.01)$. Most of the students who think they understand design better (Q4) can express ideas better with VR (Q1), while there does exist some students who may not achieve their understanding through VR. Q5 and Q6 are correlated with all the other items. That is, if a student thinks he or she has a good command of learning content and communicating the design ideas, the student also feels confident with the other statements.

Q8 investigates the subjective evaluation of one's design outcome. It has the positive correlations with Q5, Q6, and Q7 $(r=0.292,0.292$, and 0.258$)$. This shows that the students who are satisfied with their design results grasp the content and communicate their ideas better in the design process. Q9 probes the students' attitude towards the implementation of design through VR. Its positive correlations with Q3, Q6 and $\mathrm{Q} 10(\mathrm{r}=0.332,0.348$, and 0.353$)$ are another evidence to support our VR-aided approach to teach design. Although the descriptive statistics shows that Q9 has a high mean rating, there is no significant correlation between it and Q1. We hypothesis that even though students recognise the usefulness of VR in design, it does not necessarily mean that they can confidently use VR for design. This seems to be true in most cases, where the appreciation of a value does not always lead to the practical skills manifesting that value.

Q10 explores the students' acceptance of our pedagogical arrangements. It has a strong correlation with Q11 and Q12 ( $\mathrm{r}$ $=0.506$ and 0.416 ). This reflects that the students agree with the VR-aided approach and the fitness to their learning habits. The positive correlation between Q11 and Q12 $(r=0.557)$ also further supports this finding. On the other hand, the correlation between Q12 and Q5 $(r=0.479)$ confirms that the learning modes based DCT can enhance the students' understanding and retention of the taught knowledge.

TABLE 5 | Mean plot of the questionnaire results.

\begin{tabular}{|c|c|c|c|c|c|c|c|c|c|c|c|c|}
\hline & Q1 & Q2 & Q3 & Q4 & Q5 & Q6 & Q7 & Q8 & Q9 & Q10 & Q11 & Q12 \\
\hline Mean & 3.38 & 3.75 & 4.23 & 3.82 & 3.38 & 4.02 & 4.15 & 3.82 & 4.48 & 4.18 & 4.20 & 4.12 \\
\hline Mode & 3 & 5 & 5 & $3^{a}$ & 3 & 4 & $4^{a}$ & 3 & 5 & 5 & 5 & 5 \\
\hline SD & 1.180 & 1.035 & 0.810 & 1.017 & 0.976 & 0.792 & 0.860 & 0.965 & 0.770 & 0.854 & 0.777 & 0.846 \\
\hline Variance & 1.393 & 1.072 & 0.656 & 1,034 & 0.952 & 0.627 & 0.740 & 0.932 & 0.593 & 0.792 & 0.603 & 0.715 \\
\hline Range & 4 & 3 & 2 & 4 & 4 & 3 & 3 & 4 & 2 & 3 & 2 & 2 \\
\hline
\end{tabular}

aMultiple modes exist. The smallest value is shown. 
TABLE 6 | Correlation matrix of the questionnaires.

\begin{tabular}{|c|c|c|c|c|c|c|c|c|c|c|c|c|}
\hline & Q1 & Q2 & Q3 & Q4 & Q5 & Q6 & Q7 & Q8 & Q9 & Q10 & Q11 & Q12 \\
\hline Q1 & 1 & & & & & & & & & & & \\
\hline Q2 & $0.607^{a}$ & 1 & & & & & & & & & & \\
\hline Q3 & $0.454^{a}$ & $0.535^{a}$ & 1 & & & & & & & & & \\
\hline Q4 & $0.582^{a}$ & $0.487^{a}$ & $0.608^{a}$ & 1 & & & & & & & & \\
\hline Q5 & $0.503^{a}$ & $0.499^{a}$ & $0.357^{a}$ & $0.260^{b}$ & 1 & & & & & & & \\
\hline Q6 & $0.428^{a}$ & $0.398^{a}$ & $0.337^{a}$ & $0.299^{b}$ & $0.408^{a}$ & 1 & & & & & & \\
\hline Q7 & $0.293^{b}$ & $0.328^{b}$ & $0.484^{a}$ & $0.284^{b}$ & $0.476^{a}$ & $0.519^{a}$ & 1 & & & & & \\
\hline Q8 & 0.211 & 0.174 & 0.164 & 0.207 & $0.292^{b}$ & $0.292^{b}$ & $0.258^{\mathrm{b}}$ & 1 & & & & \\
\hline Q9 & 0.184 & 0.239 & $0.332^{a}$ & $0.267^{b}$ & $0.268^{b}$ & $0.348^{a}$ & 0.196 & 0.212 & 1 & & & \\
\hline Q10 & $0.417^{\mathrm{a}}$ & $0.340^{a}$ & $0.403^{a}$ & $0.352^{\mathrm{a}}$ & $0.382^{a}$ & $0.397^{a}$ & $0.354^{a}$ & 0.227 & $0.353^{a}$ & 1 & & \\
\hline Q11 & $0.303^{b}$ & $0.506^{a}$ & $0.329^{b}$ & 0.24 & $0.389^{a}$ & $0.380^{a}$ & $0.538^{a}$ & 0.14 & 0.176 & $0.506^{a}$ & 1 & \\
\hline Q12 & $0.447^{a}$ & $0.557^{a}$ & $0.256^{\mathrm{b}}$ & $0.321^{a}$ & $0.479^{a}$ & $0.453^{a}$ & $0.418^{a}$ & 0.151 & 0.120 & $0.416^{a}$ & $0.557^{\mathrm{a}}$ & 1 \\
\hline
\end{tabular}

${ }^{a}$ Correlation is significant at the 0.01 level (2-tailed).

${ }^{b}$ Correlation is significant at the 0.05 level (2-tailed).

\section{Interview Result}

After the questionnaire survey, we randomly selected 28 students for a follow-up interview. As one of the most effective methods to collect data, interview can provide abundant data and making meaning (Warren, 2002). We adopted semi-structured interview in a one to one setting and mainly talk about the experience of the course. During the interview, we observed that almost all the students accepted VR technology as a good teaching aid. The students' positive attitude can be verified with the following quotes from the interview:

"I feel authentic in the process of using it for it is easier to generate the design."

"VR can easily concretize what I have imaged, which is impossible to do in the physical process."

"I will soon learn how to use it."

"In addition to painting and handcraft, I have mastered a new design skill."

As mentioned in the questionnaire analysis, in the interview, we focused on the students' responses related to Q1 and Q5. Some of them did not think they could skillfully use VR equipment to complete the design concept. After the interview, we found that the main cause of this phenomenon is the exposure time. Because the project is based on group work, each student's role and task in the group might not be so clear. As a result, the average usage of VR could not be guaranteed. Some students said that they did not have enough time to learn more functions of VR. So, they did not think they carried out their design tasks well. This seems to explain why the mean ratings for Q1 and Q5 are not as high as those of the other statements. In our course, we tried not to intervene in the distribution of tasks within the group. That seems to have caused the nuances of student experience.

We also interviewed the students about their understandings of the course as a whole. The response is satisfactory. Many students mentioned the words, "helpful" and "clear", when describing their overall feelings. For example, in the following quotes:

\begin{abstract}
"The combination of lectures and practices can help us understand better the course's content."

"If it is was a design course based on painting, it might not be able to show your ideas well because of the lack of painting skills. In that case, VR naturally works in 3D and intuitive for implementing ideas."
\end{abstract}

In our class observation, we noticed that VR quickly provided a visualized mean for the students to analyze and reflect on their design works. The peer's evaluation could also be used as the direction of updating and improving the work.

Many students naturally associated this course with the design courses they had experienced before and made the comparison. Although those courses were not aimed at 3D design, there were some shared principles and practices:

"Traditional design courses are taught by copying and practicing, but VR can give more fun to them."

Most students think that the VR-aided teaching mode is more in line with their learning habits. They appreciated the immersion and interaction provided by VR so that they felt less cumbersome in comparison with using the traditional $3 \mathrm{D}$ software.

"We learnt how to use VR at the early stage in the course, which reduces the learning task for the later design process."

"The feeling of design is imaginative and playful. VR can help us achieve that."

Two interviewee students gave suggestions to the course arrangement. They thought that the class time was short. Sometimes, a design task could not be completed by the end of a class. In the week after, they felt that they could not follow up with the previous design flow well. In addition, they thought it would be helpful to receive the evaluation and feedback on the progress made in the previous class. 


\section{CONCLUSION}

VR technology introduces more possibilities of education. However, its educational applications should adapt to learning objectives with a coherent design strategy. In design courses, the expression and communication of design ideas are two essential elements. Our study aimed to embed VR technology in the teaching of those elements for 3D design. In our proposed pedagogical framework, we ensure the VR-aided teaching approach covers students' remembering, understanding, applying, analysing, evaluating, and creating processes stated in the Bloom's taxonomy. The students' feedback shows that they are satisfied with the approach that helps them understand the design process and communicate their design ideas. The immersive viewing and interaction modes of VR fit well with the students' cognitive process of making and manipulating $3 \mathrm{D}$ models, which in turn enhance their design expression skills. Our findings indicate that immersive VR technology may be particularly suitable for educating practically-oriented subjects such as product design.

According to the analysis and discussion of the course feedback, we sum up the possible future work of this research. The Likertscale analysis shows that some students still have some problems of using VR software because of the varied usage time. In the following development of the course, we shall arrange more exercises with set goals to use VR for design. In the meantime, we will investigate more user-friendly VR-based 3D manipulation software. Although we chose not to intervene the task arrangement within each group in current course, it is important to make each student feel involved in the whole design process. One possible solution is to have formative assessments requiring students to report and explain their contributions along the process. This also allows the teaching staff to give intermediate feedback more frequently. While we attempt to give more freedom to and empower the students' creativity, the guidance from the teachers can provide certain assurance of the learning progress and help optimize their design outcome.

\section{REFERENCES}

Allcoat, D., and von M̈ uhlenen, A. (2018). Learning in Virtual Reality: Effects on Performance, Emotion and Engagement. Res. Learn. Technol. 26, 1-13. doi:10. 25304/rlt.v26.2140

Amran, N., Bahry, F. D. S., Yusop, Z. M., and Abdullah, S. (2011). Learning Styles of Non-science and Non-technology Students on Technical Courses in an Information Management Program. Efi 28, 325-339. doi:10.3233/efi-2010-0915

Anderson, L. W., and Bloom, B. S. (2001). A Taxonomy for Learning, Teaching, and Assessing: A Revision of Bloom's Taxonomy of Educational Objectives. London, United Kingdom: Longman.

Barari, N., RezaeiZadeh, M., Khorasani, A., and Alami, F. (2020). Designing and Validating Educational Standards for E-Teaching in Virtual Learning Environments (VLEs), Based on Revised Bloom's Taxonomy. Interact. Learn. Environ., 1-13. doi:10.1080/10494820.2020.1739078

Bevins, S., and Price, G. (2016). Reconceptualising Inquiry in Science Education. Int. J. Sci. Educ. 38, 17-29. doi:10.1080/09500693.2015.1124300

Bloom, B. S. (1956). Taxonomy of Educational Objectives: The Classification of Educational Goals. Cogn. domain.

\section{DATA AVAILABILITY STATEMENT}

The original contributions presented in the study are included in the article/Supplementary Material, further inquiries can be directed to the corresponding author.

\section{ETHICS STATEMENT}

Ethical approval was not provided for this study on human participants because the background of our research is based on teaching design courses in the cooperative secondary school. The course itself is routine and the purpose of the research is not to produce research results for specific human factors but to explore students' acceptance and evaluation of the design course. Written informed consent to participate in this study was provided by the participants' legal guardian/next of kin.

\section{AUTHOR CONTRIBUTIONS}

MN performed the experiment, data analyses, and wrote the manuscript; C-HL contributed to the conception of the study and reviewed the whole manuscript; ZY helped perform the analysis with constructive discussions.

\section{FUNDING}

This project is partially-funded by the External Research Project (RDS10120190074) and XJTLU Research Development Fund (RDF-16-02-22).

\section{ACKNOWLEDGMENTS}

We greatly appreciate the collaborated school (XJTLU-Affiliated School) and the University for their support to this project.

Bogusevschi, D., Muntean, C., and Muntean, G.-M. (2020). Teaching and Learning Physics Using 3d Virtual Learning Environment: A Case Study of Combined Virtual Reality and Virtual Laboratory in Secondary School. J. Comput. Math. Sci. Teach. 39, 5-18.

Brinson, J. R. (2015). Learning Outcome Achievement in Non-traditional (Virtual and Remote) versus Traditional (Hands-on) Laboratories: A Review of the Empirical Research. Comput. Educ. 87, 218-237. doi:10.1016/j.compedu.2015. 07.003

Bruno, F., Mattan `o, R. M., Muzzupappa, M., and Pina, M., (2007). "Design for Usability in Virtual Environment," in DS 42: Proceedings of ICED 2007, the 16th International Conference on Engineering Design, Paris, France, 827-828. 28.-31.07.

Cai, S., Liu, E., Yang, Y., and Liang, J.-C. (2019). Tablet-based AR Technology: Impacts on Students' Conceptions and Approaches to Learning Mathematics According to Their Self-Efficacy. Br. J. Educ. Technol. 50, 248-263. doi:10.1111/ bjet. 12718

Camba, J. D., Soler, J. L., and Contero, M. (2017). "Immersive Visualization Technologies to Facilitate Multidisciplinary Design Education," in International Conference on Learning and Collaboration Technologies. Springer, 3-11. doi:10.1007/978-3-319-58509-3_1 
Chung, C.-c., Tung, C.-C., and Lou, S.-J. (2020). Research on Optimization of Vr Welding Course Development with Anp and Satisfaction Evaluation. Electronics 9, 1673. doi:10.3390/electronics9101673

Cuevas, J., and Dawson, B. L. (2018). A Test of Two Alternative Cognitive Processing Models: Learning Styles and Dual Coding. Theor. Res. Educ. 16, 40-64. doi:10.1177/1477878517731450

Cuevas, J. (2016). An Analysis of Current Evidence Supporting Two Alternate Learning Models: Learning Styles and Dual Coding. J. Educ. Sci. Psychol. 6, 1-13.

Dabbagh, N. (2003). Scaffolding: An Important Teacher Competency in Online Learning. Techtrends Tech. Trends 47, 39-44. doi:10.1007/bf02763424

Dahlstrom, E., and Bichsel, J. (2014). ECAR Study of Undergraduate Students and Information Technology, 2014. Educause, 1-50.

Demirbas, O. O., and Demirkan, H. (2003). Focus on Architectural Design Process through Learning Styles. Des. Stud. 24, 437-456. doi:10.1016/s0142-694x(03) 00013-9

Demirkan, H., and Demirbas, O. O. (2008). Focus on the Learning Styles of Freshman Design Students. Des. Stud. 29, 254-266. doi:10.1016/j.destud.2008. 01.002

Dinis, F. M., Guimaraes, A. S., Carvalho, B. R., and Martins, J. P. P. (2017). Virtual and Augmented Reality Game-Based Applications to Civil Engineering Education in 2017 IEEE Global Engineering Education Conference (EDUCON) (. IEEE), 1683-1688.

Fowler, C. (2015). Virtual Reality and Learning: Where Is the Pedagogy? $\mathrm{Br}$. J. Educ. Technol. 46, 412-422. doi:10.1111/bjet.12135

Funnell, M. G., Corballis, P. M., and Gazzaniga, M. S. (2001). Hemispheric Processing Asymmetries: Implications for Memory. Brain Cogn. 46, 135-139. doi:10.1016/s0278-2626(01)80051-8

Funnell, M. G., Corballis, P. M., and Gazzaniga, M. S. (2003). Temporal Discrimination in the Split Brain. Brain Cogn. 53, 218-222. doi:10.1016/ s0278-2626(03)00113-1

Gazzaniga, M. S. (2005). Forty-five Years of Split-Brain Research and Still Going strong. Nat. Rev. Neurosci. 6, 653-659. doi:10.1038/nrn1723

Graham, M. A. (2020). Deconstructing the Bright Future of Steam and Design Thinking. Art Educ. 73, 6-12. doi:10.1080/00043125.2020.1717820

Guerrero, G., Ayala, A., Mateu, J., Casades, L., and Alamán, X. (2016). Integrating Virtual Worlds with Tangible User Interfaces for Teaching Mathematics: A Pilot Study. Sensors 16, 1775. doi:10.3390/s16111775

Hamurcu, A. (2018). "2018 2nd International Symposium on Multidisciplinary Studies and Innovative Technologies (ISMSIT)," in User Insights about Using Immersive Virtual Reality in Industrial Design Studio Courses. IEEE, 1-8.

Hodes, C. L. (1998). Understanding Visual Literacy through Visual Information Processing. J. Vis. Literacy 18, 131-136. doi:10.1080/23796529.1998. 11674534

Jensen, L., and Konradsen, F. (2018). A Review of the Use of Virtual Reality HeadMounted Displays in Education and Training. Educ. Inf. Technol. 23, 1515-1529. doi:10.1007/s10639-017-9676-0

Jessen, F., Heun, R., Erb, M., Granath, D.-O., Klose, U., Papassotiropoulos, A., et al. (2000). The Concreteness Effect: Evidence for Dual Coding and Context Availability. Brain Lang. 74, 103-112. doi:10.1006/brln.2000.2340

Jimeno-Morenilla, A., anchez-Romero, J. L., Coll-Miralles, R., and Coll-Miralles, R. (2016). Using Virtual Reality for Industrial Design Learning: a Methodological Proposal. Behav. Inf. Technol. 35, 897-906. doi:10.1080/0144929x.2016. 1215525

Jones, M. G., Hite, R., Childers, G., Corin, E., Pereyra, M., and Chesnutt, K. (2016). Perceptions of Presence in 3-d, Haptic-Enabled, Virtual Reality Instruction. Int. J. Educ. Inf. Techno 10, 73-81.

Krokos, E., Plaisant, C., and Varshney, A. (2019). Virtual Memory Palaces: Immersion Aids Recall. Virtual Reality 23, 1-15. doi:10.1007/s10055-0180346-3

Kuo, H.-C., Burnard, P., McLellan, R., Cheng, Y.-Y., and Wu, J.-J. (2017). The Development of Indicators for Creativity Education and a Questionnaire to Evaluate its Delivery and Practice. Thinking Skills and Creativity 24, 186-198. doi:10.1016/j.tsc.2017.02.005

Kvan, T., and Jia, Y. (2005). Students' Learning Styles and Their Correlation with Performance in Architectural Design Studio. Des. Stud. 26, 19-34. doi:10.1016/ j.destud.2004.06.004
Laurillard, D., Charlton, P., Craft, B., Dimakopoulos, D., Ljubojevic, D., Magoulas, G., et al. (2013). A Constructionist Learning Environment for Teachers to Model Learning Designs. J. Comput. Assist. Learn. 29, 15-30. doi:10.1111/j. 1365-2729.2011.00458.x

Lee, E. A.-L., and Wong, K. W. (2008). A Review of Using Virtual Reality for Learning. Trans. edutainment, 231-241. doi:10.1007/978-3-540-69744-2_18

Liang, Y.-W., Lee, A. S., and Liu, S.-F. (2016). A Study on Design-Oriented Demands of Vr via Zmet-Qfd Model for Industrial Design Education and Students' Learning. Eurasia J. Math. Sci. Technol. Education12, 1205-1219.

Lin, C.-H., and Hsu, P.-H. (2017). Integrating Procedural Modelling Process and Immersive Vr Environment for Architectural Design Education. In MATEC Web Of Conferences (EDP Sciences), 104, 03007.

Liu, X., Liu, C.-H., and Li, Y. (2020). The Effects of Computer-Assisted Learning Based on Dual Coding Theory. Symmetry 12, 701. doi:10.3390/ sym 12050701

Lovelace, M. K. (2005). Meta-analysis of Experimental Research Based on the dunn and dunn Model. J. Educ. Res. 98, 176-183. doi:10.3200/joer.98.3.176-183

Maheshwari, I., and Maheshwari, P. (2020). Effectiveness of Immersive Vr in Stem Education. In 2020 Seventh International Conference On Information Technology Trends (ITT). (IEEE), 7-12. doi:10.1109/itt51279.2020.9320779

Mahlios, M. (2001). Matching Teaching Methods to Learning Styles. Child. Stress Understanding helping, 65-73.

Mayer, R. E., and Anderson, R. B. (1991). Animations Need Narrations: An Experimental Test of a Dual-Coding Hypothesis. J. Educ. Psychol. 83, 484-490. doi:10.1037/0022-0663.83.4.484

Mazoyer, B., Tzourio-Mazoyer, N., Mazard, A., Denis, M., and Mellet, E. (2002). Neural Bases of Image and Language Interactions. Int. J. Psychol. 37, 204-208. doi:10.1080/00207590244000007

Meyer, O. A., Omdahl, M. K., and Makransky, G. (2019). Investigating the Effect of Pre-training when Learning through Immersive Virtual Reality and Video: A media and Methods experiment. Comput. Educ. 140, 103603. doi:10.1016/j. compedu.2019.103603

Muscat, M., and Mollicone, P. (2012). Using Kolb's Learning Cycle to Enhance the Teaching and Learning of Mechanics of Materials. Int. J. Mech. Eng. Educ. 40, 66-78. doi:10.7227/ijmee.40.1.10

Naimie, Z., Siraj, S., Ahmed Abuzaid, R., and Shagholi, R. (2010). Hypothesized Learners' Technology Preferences Based on Learning Style Dimensions. Turkish Online J. Educ. Technology-TOJET 9, 83-93.

Nguyen, V. T., and Dang, T. (2017). "2017 IEEE International Symposium on Mixed and Augmented Reality (ISMAR-Adjunct)," in Setting up Virtual Reality and Augmented Reality Learning Environment in unity. IEEE, 315-320.

Noel, L.-A., and Liub, T. L. (2017). Using Design Thinking to Create a New Education Paradigm for Elementary Level Children for Higher Student Engagement and success. Des. Technol. Educ. 22, n1

Ogden, W. R. (2003). Reaching All the Students: The Feedback Lecture. J. Instructional Psychol. 30, 22-28.

Paivio, A. (1991). Dual Coding Theory: Retrospect and Current Status. Can. J. Psychology/Revue canadienne de Psychol. 45, 255-287. doi:10.1037/ h0084295

Pashler, H., McDaniel, M., Rohrer, D., and Bjork, R. (2008). Learning Styles. Psychol. Sci. Public Interest 9, 105-119. doi:10.1111/j.1539-6053.2009. 01038.x

Pellas, N., and Boumpa, A. (2017). Blending the CoI Model with Jigsaw Technique for Pre-service Foreign Language Teachers' Continuing Professional Development Using Open Sim and Sloodle. Educ. Inf. Technol. 22, 939-964. doi:10.1007/s10639-016-9465-1

Prezhdarova, V., and Pastarmadzhieva, D. (2020). Ensuring the Security of Youth in the Online World: The Potential of the Digital Art and Steam Education. Tjs 18, 183-188. doi:10.15547/tjs.2020.03.001

Radianti, J., Majchrzak, T. A., Fromm, J., and Wohlgenannt, I. (2020). A Systematic Review of Immersive Virtual Reality Applications for Higher Education: Design Elements, Lessons Learned, and Research Agenda. Comput. Educ. 147, 103778. doi:10.1016/j.compedu.2019.103778

Sampaio, A. Z., Ferreira, M. M., Rosário, D. P., and Martins, O. P. (2010). 3d and Vr Models in Civil Engineering Education: Construction, Rehabilitation and Maintenance. Automation in Construction 19, 819-828. doi:10.1016/j.autcon. 2010.05.006 
Sharps, M. J., Price, J. L., and Bence, V. M. (1996). Visual and Auditory Information as Determinants of Primacy Effects. J. Gen. Psychol. 123, 123-136. doi:10.1080/ 00221309.1996 .9921266

Shih, S.-L., Ou, S.-J., Huang, Y.-C., and Mu, Y.-C. (2019). The Difficulties and Countermeasures of Applying Virtual Reality to Industrial Design Education. In Proceedings of the 2019 3rd International Conference on Education and Multimedia Technology. 269-272. doi:10.1145/3345120.3345150

Siew, N. M. (2017). Integrating Stem in an Engineering Design Process: The Learning Experience of Rural Secondary School Students in an Outreach challenge Program. Eurasia Proc. Educ. Soc. Sci. 6, 128-141.

Sims, E., and Shreeve, A. (2012). Signature Pedagogies in Art and Design. Exploring more signature pedagogies: Approaches Teach. disciplinary habits mind, 55-67.

Stanberry, A. M., and Azria-Evans, M. (2001). Perspectives in Teaching Gerontology: Matching Strategies with Purpose and Context. Educ. Gerontol. 27, 639-656. doi:10.1080/036012701317117884

Stone, R. (2001). Virtual Reality for Interactive Training: an Industrial Practitioner's Viewpoint. Int. J. Human-Computer Stud. 55, 699-711. doi:10. 1006/ijhc.2001.0497

Suh, J. M., and Moyer-Packenham, P. S. (2007). The Application of Dual Coding Theory in Multi-Representational Virtual Mathematics Environments. In Proceedings of the 31st Conference of the International Group for the Psychology of Mathematics Education (PME Seoul, Korea), 4, 209-216.

Sulaiman, H., Ibrahim, N., Latif, R. A., and Yusof, A. M. (2020). "Students and Teachers' Perception on Future Use of Virtual Reality (Vr) in Learning Physics: A Preliminary Analysis," In 2020 IEEE Conference on E-Learning, E-Management and E-Services. IEEE, 1-6.IC3e

Takala, T. M., Malmi, L., Pugliese, R., and Takala, T. (2016). Empowering Students to Create Better Virtual Reality Applications: A Longitudinal Study of a Vr Capstone Course.Informatics Educ. 15, 287-317.

Tang, Y. M., Au, K. M., Lau, H. C. W., Ho, G. T. S., and Wu, C. H. (2020). Evaluating the Effectiveness of Learning Design with Mixed Reality (Mr) in Higher Education. Virtual Reality 24, 797-807. doi:10.1007/s10055-020-00427-9
Vande Zande, R., Warnock, L., Nikoomanesh, B., and Van Dexter, K. (2014). The Design Process in the Art Classroom: Building Problem-Solving Skills for Life and Careers. Art Educ. 67, 20-27. doi:10.1080/00043125.2014.11519294

Wang, E. (2001). “31st Annual Frontiers in Education Conference. Impact on Engineering and Science Education. Conference Proceedings (Cat. No. 01CH37193)," in Teaching Freshmen Design, Creativity and Programming with Legos and Labview, 3. (IEEE), F3G-11372.

Warren, C. (2002). Qualitative Interviewing. Handbook interview Res. Context method 839101. doi:10.4135/9781412973588

Welcome, S. E., Paivio, A., McRae, K., and Joanisse, M. F. (2011). An Electrophysiological Study of Task Demands on Concreteness Effects: Evidence for Dual Coding Theory. Exp. Brain Res. 212, 347-358. doi:10. 1007/s00221-011-2734-8

Zhang, H., Yu, L., Ji, M., Cui, Y., Liu, D., Li, Y., et al. (2020). Investigating High School Students' Perceptions and Presences under VR Learning Environment. Interact. Learn. Environ. 28, 635-655. doi:10.1080/ 10494820.2019.1709211

Zhang, R. (2018). Evolution of Vr Technology to Art Design Education in the Digital Age. In 2018 8th International Conference On Social Science and Education Research (SSER 2018) (Atlantis Press). doi:10.2991/sser-18. 2018.143

Conflict of Interest: The authors declare that the research was conducted in the absence of any commercial or financial relationships that could be construed as a potential conflict of interest.

Copyright (C) $2021 \mathrm{Niu}, \mathrm{Lo}$ and Yu. This is an open-access article distributed under the terms of the Creative Commons Attribution License (CC BY). The use, distribution or reproduction in other forums is permitted, provided the original author(s) and the copyright owner(s) are credited and that the original publication in this journal is cited, in accordance with accepted academic practice. No use, distribution or reproduction is permitted which does not comply with these terms. 